\title{
Effects of wave loading conditions on the fragility of pile-supported wharves/piers
}

\author{
Georgios P. Balomenos, Rice University, georgios.p.balomenos@rice.edu \\ Jamie E. Padgett, Rice University, jamie.padgett@rice.edu
}

\section{INTRODUCTION}

Pile-supported wharves/piers are often subjected to extreme forces caused by coastal hazards. For instance, hurricanes Katrina (2005) and Wilma (2005) caused significant structural damage to pile-supported piers (Gutierrez et al. 2006) and wharves (Bardi et al. 2007), respectively. The problem becomes more pressing as the hazard exposure of these structures evolves with sea level rise caused by climate change (Lamberti et al. 2011). Thus, in light of gaps in the risk assessment of these structures in hurricane prone regions, Balomenos and Padgett (2018a) proposed the first probabilistic framework for developing analytical fragility models for pile-supported wharves/piers vulnerable to hurricaneinduced storm surge and waves. Then, Balomenos and Padgett (2018b) adopted this framework to provide an initial exploration into the sensitivity of the fragility estimate to epistemic uncertainties in the wave load model. However, considering that the wave period may have a significant variation at or near the coast based on reported periods during hurricanes Katrina and Rita (Dietrich et al. 2011), this study further explores the influence of hazard parameter variation on the resulting failure probability of these structures, while propagating uncertainties in other parameters such as concrete compressive strength, deck thickness, etc.

\section{WAVE FORCE}

The applied wave force is estimated using mathematical expressions developed by McConnell et al. (2004). The vertical impact force is proportional to the quasi-static force and is calculated as

$$
F_{v, i m p}=F_{v, q s} \frac{a_{v, i m p}}{\left(t_{r} / T_{m}\right)^{b_{v, i m p}}}
$$

where $\left(t_{r} / T_{m}\right)$ is the dimensionless rise time, $a_{v, \text { imp }}, b_{v, \text { imp }}$ are empirical coefficients that depend on the selected predicted method (moderate or conservative), and $F_{v, q s}$ is the quasi-static force calculated as

$$
F_{v, q s}=\left(F_{v}^{*} \frac{a_{v, q s}}{\left[\frac{\left(\eta_{\max }-Z_{c}\right)}{H_{s}}\right]^{b_{v, q s}}}\right) \times \varepsilon_{1}
$$

where $F_{v}^{*}$ is the vertical basic wave force, $\eta_{\max }$ is the maximum crest elevation, $Z_{c}$ is the relative surge elevation, $H_{s}$ is the significant wave height, $a_{v, q s}, b_{v, q s}$ are empirical coefficients that depend on the deck location (seaward or internal), and $\varepsilon_{1}$ is the model error term introduced by Balomenos and Padgett (2018a) to capture the scatter of the data used by McConnell et al. (2004).

\section{FAILURE MODE}

The examined failure mode is the uplift of the deck subjected to vertical wave forces caused by storm surge and waves, which has been the main cause of destruction of decks during past storm events (Gutierrez et al. 2006; Bardi et al. 2007). Balomenos and Padgett (2018a), also examined the shear, and flexural failure of dowelled deck-pile connections, and they found that the uplift was the dominant failure mode for the examined structural details and range of hazard parameters.

\section{FRAGILITY ANALYSIS}

The probability of the deck to experience uplift is conditioned on hazard intensity measures and is calculated as

$$
p_{f}=P[C-D \leq 0 \mid I M s]
$$

where $p_{f}$ is the failure probability, IMs are the intensity measures (i.e., $H_{\max }, Z_{c}, T_{m}$ ), $H_{\max }$ is the maximum wave height estimated from $H_{s}$ using AASHTO (2008), $T_{m}$ is the mean wave period, $C$ and $D$ are the uplift capacity and demand, respectively. Thus, this study develops fragility curves conditioned on three parameters, instead of two used in Balomenos and Padgett (2018a, 2018b). For each combination of $H_{\max }, Z_{c}$ and $T_{m}, 10,000$ samples are generated for selected random variables affecting both demand and capacity, via a Monte Carlo procedure using Latin Hypercube Sampling (McKay et al. 1979). The selected random variables are the wave period corresponding to $H_{\max }$, the dimensionless rise time, the deck thickness, the compressive strength and unit weight of concrete, and the yield strength of steel (Balomenos and Padgett 2018a). Two partial moment (PM) connections are examined (Balomenos and Padgett 2018b), which consist of mild steel headed dowels grouted into the pile (Harn et al. 2010). The primary difference in these connections is the anchoring of the dowels, i.e., dowels are anchored inside (IN) or outside (OUT) of the compression zone of the deck's top mat reinforcement.

\section{RESULTS}

Fragility analysis indicates that there is $27 \%$ probability for a $1.15 \mathrm{~m}$ seaward submerged deck to experience uplift when subjected to wave heights of $2 \mathrm{~m}$, while this probability is decreased to $5 \%$ when the dowels are developed inside of the compression zone (Figure 1). These estimates reflect uncertainty in structure, material and select wave parameters while adopting a fixed mean wave period of $6 \mathrm{~s}$. Given that this period may vary at or near the coast, the vulnerability of the previous connections is also examined for different mean wave periods, i.e., for 3 and 9 seconds. As shown in Figure 2, the increase in mean wave period to $9 \mathrm{~s}$ has a negligible effect on the fragility while the reduced period begins to show appreciable shifts in failure probability, i.e., the $27 \%$ uplift failure probability at the aforementioned surge elevation and wave height is increased to almost $40 \%$ when the period decreases to $3 \mathrm{~s}$ (Figure 2). This shift in failure probability is much higher for a deck that has not experienced inundation (Figure 3 ). Thus, short wave periods are expected to affect the uplift fragility of decks with adequate clearance, while the uplift fragility of inundated decks shows smaller shifts. Figure 4 shows the propagation of the uplift probability for different mean wave periods, for a submerged deck subjected to a wave height of $2.11 \mathrm{~m}$. Changes in the uplift probability are almost constant after the value of $5 \mathrm{~s}$ for both deck conditions (inundated or not), although these changes are sharper for a seaward deck exposed to short period waves.

\section{CONCLUSIONS}

This study aims to shed light on the fragility of common pilesupported port connections subjected to coastal hazards and how, amidst other uncertainties, different wave loading 
conditions affect their expected performance during these extreme events. Thus, the uplift probability is conditioned to three intensity measures. Fragility analysis shows that waves with a short period will increase the uplift probability, no matter deck condition (inundated or not), and sharper changes are expected in this probability for a seaward deck. Although, waves with longer periods are not expected to bias the developed fragilities, future studies should examine the role of epistemic uncertainty in different predicted wave load models in affecting the fragility.

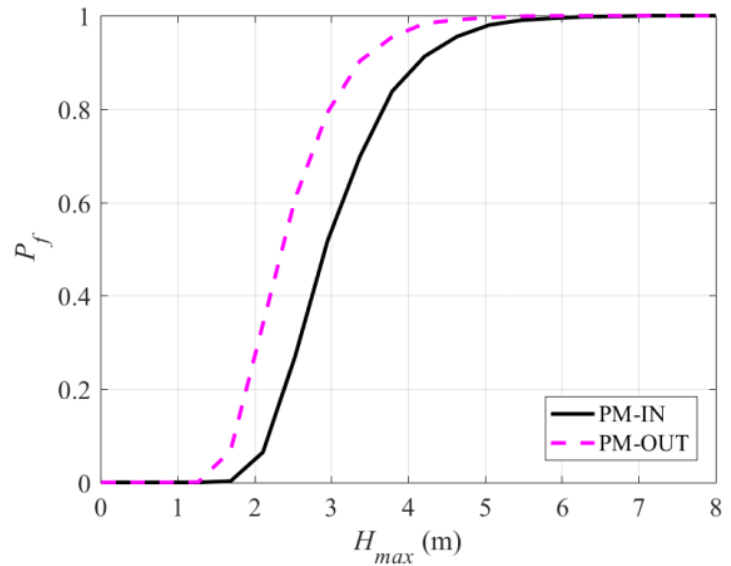

Figure 1 - Uplift fragility curve for $1.15 \mathrm{~m}$ submerged seaward deck (Note: $\mathrm{PM}=$ partial moment connection; IN = dowels anchored inside of the compression zone; OUT = dowels anchored outside of the compression zone)

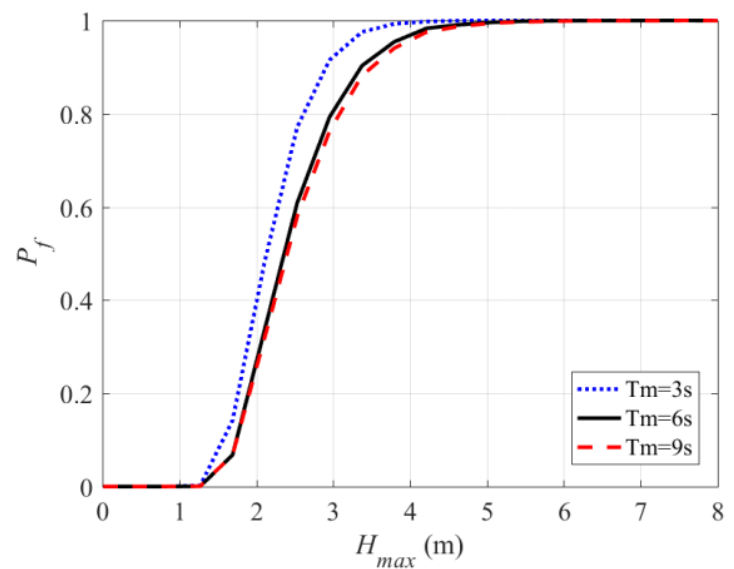

Figure 2 - Uplift fragility curves for $1.15 \mathrm{~m}$ submerged seaward deck: PM-OUT connection

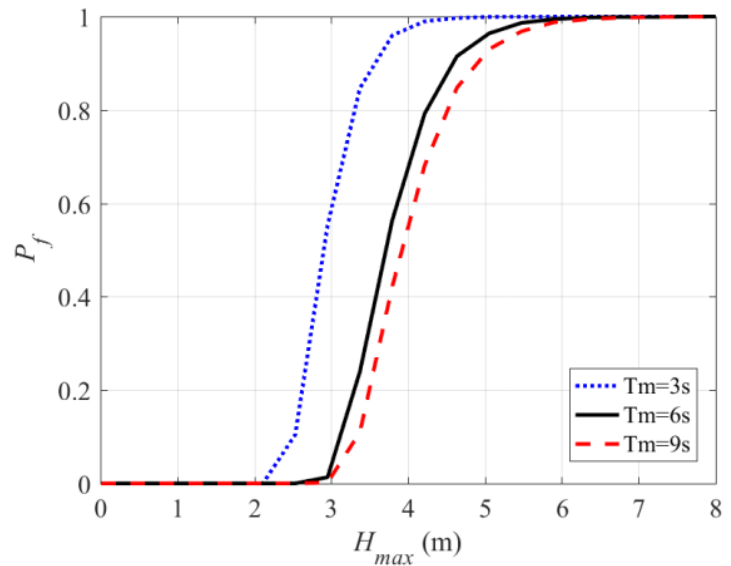

Figure 3 - Uplift fragility curves for seaward deck standing $1.15 \mathrm{~m}$ above water: PM-OUT connection

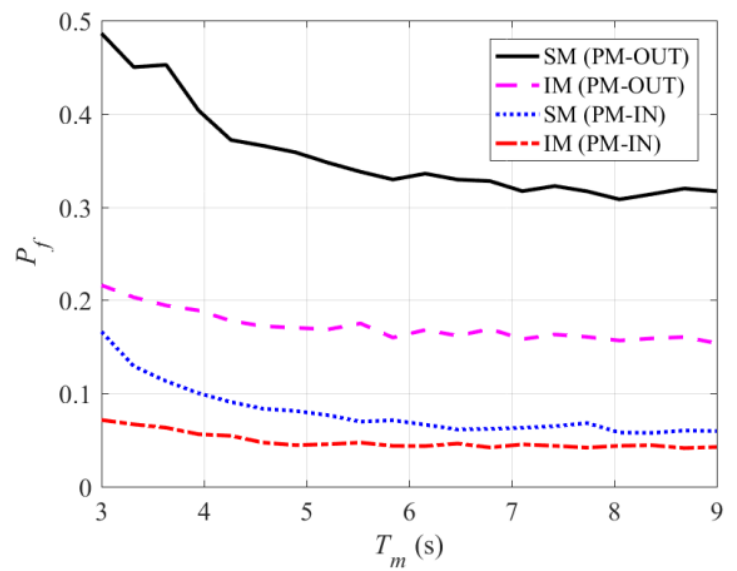

Figure 4 - Uplift Probability for $1.15 \mathrm{~m}$ submerged deck subjected to a $2.11 \mathrm{~m}$ wave height (Note: SM = seaward deck moderate prediction; IM = internal deck moderate prediction)

\section{ACKNOWLEDGEMENTS}

The authors grateful acknowledge the support of this research by the Shell Center for Sustainability. Any opinions, findings, conclusions, and recommendations expressed in this material are those of the authors and do not necessarily reflect the views of the sponsor.

\section{REFERENCES}

AASHTO (2008): Guide specifications for bridges vulnerable to coastal storms, Washington, DC.

Balomenos, Padgett (2018a): Fragility analysis of pilesupported wharves and piers exposed to storm surge and waves, Journal of Waterway, Port, Coastal, and Ocean Engineering, ASCE, 144(2), 04017046.

Balomenos, Padgett (2018b): Vulnerability assessment of port structures subjected to storm surge and waves, Proc., ASCE Structures Congress 2018, Fort Worth, TX, pp. 1-15.

Bardi, Ostbo, Fenical, Tirindelli (2007): Cozumel's International Cruise Terminal: Hurricane Wilma Recovery and Reconstruction, Proc., ASCE Ports 2007, San Diego, CA, pp. 1-10.

Dietrich, Zijlema, Westerink, Holthuijsen, Dawson, Luettich, Jensen, Smith, Stelling, Stone (2011): Modeling hurricane waves and storm surge using integrallycoupled, scalable computations, Coastal Engineering, ELSEVIER, 58(1), pp. 45-65.

Gutierrez, Cresanti, Jeffrey (2006): Performance of physical structures in Hurricane Katrina and Hurricane Rita: A reconnaissance report, NIST, Washington, DC.

Harn, Mays, Johnson (2010): Proposed Seismic Detailing Criteria for Piers and Wharves, Proc., ASCE Ports 2010, Jacksonville, FL, pp. 460-469.

Lamberti, Martinelli, Gabriella Gaeta, Tirindelli, Alderson (2011): Experimental spatial correlation of wave loads on front decks, Journal of Hydraulic Research, TAYLOR \& FRANCIS, 49(sup1), pp. 81-90.

McConnell, Allsop, Cruickshank (2004): Piers, jetties and related structures exposed to waves: guidelines for hydraulic loadings, THOMAS TELFORD, London, UK. McKay, Beckman, Conover (1979): Comparison of three methods for selecting values of input variables in the analysis of output from a computer code, Technometrics, TAYLOR \& FRANCIS, 21(2), pp. 239-245 